Gut, 1976, 17, 959-964

\title{
Galactose elimination capacity as a prognostic index in patients with fulminant liver failure
}

\author{
L. RANEK, P. BUCH ANDREASEN, AND N. TYGSTRUP
}

From the Rigshospitalet, Medical Department A, Division of Hepatology, Copenhagen, Denmark

SUMMARY In 25 patients with fulminant hepatic failure the prognostic value of a quantitative liver function test, the galactose elimination capacity, was assessed and compared with routine liver function tests and clinical features. The galactose elimination capacity was significantly higher $(P<0.05)$ in the five patients who survived than in the 20 patients who died. None of the other liver function tests was significantly different. The values of the galactose elimination capacity overlapped considerably between survivors and non-survivors, but all patients with a galactose elimination capacity below $12.8 \mu \mathrm{mol}$ galactose/min and $\mathrm{kg}$ body weight died. The disease among most patients who died having a galactose elimination capacity greater than $13 \mu \mathrm{mol}$ ran a subacute course. It is suggested that quantitative liver function tests be included when new treatments of fulminant hepatic failure are investigated.

The high mortality in acute liver failure (Saunders and Terblanche, 1975), and the complete recovery of patients who survive (Karvountzis et al., 1974) has been a strong impulse to apply drastic, expensive, and perhaps also hazardous therapeutic measures (Eiseman et al., 1965; Trey et al., 1966; Burnell et al., 1973; Gazzard et al., 1974). However, none of these treatments is of proven value, and it cannot be excluded that recovery, when it occurs, is spontaneous. This makes it highly desirable to identify patients with a high chance of recovery. Clinical features and laboratory tests have been found to contain little, if any, prognostic information.

The present study aims at elucidation of the prognostic value of a quantitative liver test, the galactose elimination capacity, in patients with acute liver failure.

\section{Methods}

All patients were admitted to this department because of impending or manifest acute liver failure with hepatic encephalopathy. One patient (no. 15) had uncomplicated hepatitis beginning 115 days before the actual admission. She was treated in another hospital and discharged after two months but readmitted 43 days later because her condition

Address for correspondence: $L$. Ranek, Medical Department A, Division of Hepatology, Rigshospitalet, 9 Blegdamsvej, DK-2100 Copenhagen Ø, Denmark.

Received for publication 14 July 1976 had relapsed. Eight days later she developed hepatic coma. Otherwise no previous liver disease was suspected in any of the patients. Only patients reaching coma grade III (Trey et al., 1966) were included in the study. The sex, age, and aetiology of the liver disease are shown in Table 1. Sixteen of the patients were females, and nine were males. The assumed aetiology of the liver disease (Table 1) was virus hepatitis in 19 patients. Twelve of these were classified as type $A$ hepatitis. $\mathrm{HB}_{8} \mathrm{Ag}$ was not investigated in two of these (nos. 7 and 15) and was negative in the others. With a classification based on epidemiological data seven of the patients were classified as type $\mathrm{B}$ hepatitis. $\mathrm{HB}_{\mathrm{B}} \mathrm{Ag}$ was positive in three (nos. 16,17,19), negative in three (nos. 3, 4, 20), and not performed in one (no. 18). Drug hepatitis was suspected in six patients, five of whom had recently been exposed to halothane and one who had been treated with ryfamycin (Rifampicine) and isoniazid (Isoniazide).

All patients were treated in the intensive care liver unit by trained personnel and received standard anticoma treatment, consisting of $20 \%$ glucose via a gastric tube as the only supply of calories, sterilisation of the gut with Neomycin, $4 \mathrm{~g}$ daily, and purgation with magnesium sulphate. Additional treatment (Table 1) consisted of infusion of fresh frozen plasma, corticosteroids, from 30 to $80 \mathrm{~g}$ prednisone daily, exchange blood transfusions $(5000 \mathrm{ml})$, or extracorporeal pig liver perfusions (Ranek et al., 1971). Assisted respiration through a nasotracheal 
Table 1 Sex, age, and aetiology of hepatic failure in 25 patients: duration of disease and coma, and final outcome, and galactose elimination capacity

\begin{tabular}{|c|c|c|c|c|c|c|c|c|}
\hline \multirow{2}{*}{$\begin{array}{l}\text { Case } \\
\text { no. }\end{array}$} & \multirow[t]{2}{*}{$\operatorname{Sex}$} & \multirow{2}{*}{$\begin{array}{l}\text { Age } \\
(y r)\end{array}$} & \multirow[t]{2}{*}{ Aetiology } & \multicolumn{3}{|c|}{ Duration (days) } & \multirow{2}{*}{$\begin{array}{l}\text { Galactose elimina- } \\
\text { tion capacity } \\
\left(\mu \mathrm{mol} \cdot \min ^{-1} \cdot \mathrm{kg}^{-1}\right)\end{array}$} & \multirow[t]{2}{*}{ Outcome } \\
\hline & & & & $\begin{array}{l}\text { Disease } \\
\text { before adm. }\end{array}$ & $\begin{array}{l}\text { Coma } \\
\text { before adm. }\end{array}$ & $\begin{array}{l}\text { Coma } \\
\text { during adm. }\end{array}$ & & \\
\hline 1 & $\mathbf{F}$ & 22 & VH/A & 4 & 1 & 3 & $21 \cdot 7$ & Survived \\
\hline 2 & $\mathbf{M}$ & 44 & VH/A & 10 & 1 & 3 & $14 \cdot 4$ & - \\
\hline 3 & $\mathbf{M}$ & 25 & VH/B & 30 & 4 & 1 & $16 \cdot 2$ & - \\
\hline 4 & $\mathbf{M}$ & 25 & VH/B & 5 & 2 & 13 & $12 \cdot 8$ & - \\
\hline 5 & $\mathbf{M}$ & 45 & DH (hal) & 7 & 1 & 3 & $22 \cdot 8$ & - \\
\hline 6 & $\mathbf{F}$ & 17 & VH/A & 37 & $i$ & 16 & $19 \cdot 5$ & Died \\
\hline 7 & $\mathbf{F}$ & 24 & VH/A & 26 & 1 & 6 & $11 \cdot 1$ & - \\
\hline 8 & $\mathbf{F}$ & 25 & VH/A & 9 & 1 & 3 & $9 \cdot 5$ & - \\
\hline 9 & $\mathbf{F}$ & 32 & VH/A & 15 & 1 & 4 & $11 \cdot 8$ & - \\
\hline 10 & $\mathbf{F}$ & 37 & VH/A & 30 & 4 & 3 & $9 \cdot 3$ & - \\
\hline 11 & $\mathbf{F}$ & 42 & VH/A & 60 & 9 & 4 & $21 \cdot 2$ & - \\
\hline 12 & $\mathbf{F}$ & 63 & VH/A & 30 & 2 & 11 & $15 \cdot 6$ & - \\
\hline 13 & $\mathbf{F}$ & 63 & VH/A & 30 & 8 & 24 & $14 \cdot 2$ & - \\
\hline 14 & $\mathbf{M}$ & 63 & VH/A & 10 & 3 & 4 & $5 \cdot 8$ & - \\
\hline 15 & $\mathbf{F}$ & 69 & VH/A & 115 & 2 & 12 & $14 \cdot 3$ & - \\
\hline 16 & $\mathbf{F}$ & 24 & $\mathrm{VH} / \mathrm{B}$ & 7 & 1 & 2 & 6.8 & - \\
\hline 17 & $\mathbf{F}$ & 28 & $\mathbf{V H} / \mathbf{B}$ & 28 & 1 & 3 & $11 \cdot 8$ & - \\
\hline 18 & $\mathbf{M}$ & 44 & VH/B & 18 & 1 & 16 & $10 \cdot 3$ & - \\
\hline 19 & $\mathbf{M}$ & 57 & VH/B & 13 & 2 & 1 & $14 \cdot 9$ & - \\
\hline 20 & $\mathbf{M}$ & 62 & VH/B & 14 & 2 & 4 & 6.8 & - \\
\hline 21 & $\mathbf{F}$ & 47 & DH (hal) & 4 & 0 & 10 & 16.9 & - \\
\hline 22 & $\mathbf{F}$ & 51 & DH (hal) & 11 & 0 & 22 & $12 \cdot 1$ & - \\
\hline 23 & $\mathbf{F}$ & 54 & DH (hal) & 34 & 0 & 42 & $13 \cdot 9$ & - \\
\hline 24 & $\mathbf{F}$ & 56 & DH (hal) & 4 & 1 & 6 & 5.6 & - \\
\hline 25 & $\mathbf{M}$ & 62 & DH (Rifamp. & 5 & 1 & 5 & $13 \cdot 0$ & - \\
\hline
\end{tabular}

hal: halothane.

tube was initiated before hypoxia or hypercapnia developed. Peritoneal dialysis was performed if renal failure developed. Blood was analysed regularly for the following components: haemoglobin, sodium, potassium, creatinine, urea, $\mathrm{pCO}_{2}, \mathrm{O}_{2}$ saturation, standard bicarbonate, base excess, prothrombin, bilirubin, alanine aminotransferase, and alkaline phosphatases. Blood glucose was examined four times daily. Serum ammonia was examined at various intervals, usually every second or third day.

Electroencephalography (EEG) was performed regularly during the encephalopathic period until the patient either died or recovered. If the EEG revealed no activity, a cervical arteriography was performed. If intracerebral circulation could not be demonstrated, the patient was considered brain dead.

The galactose elimination capacity was determined either shortly after admission or at the time when the patient developed encephalopathy in the department. The original procedure was modified as follows: a fixed dose of $25 \mathrm{~g}$ galactose was injected intravenously in the course of five minutes. Capillary blood samples were drawn from the ear lobe at intervals of five minutes from 25 to 60 minutes after start of the injection, and a urine sample was collected after four hours (except in anuric patients). Galactose concentrations were determined enzymatically (Kurz and Wallanfalz, 1970), and the galactose elimination capacity was computed (Hewlett-Packard 9810) with a programme providing corrections for urinary excretion and uneven distribution of galactose (Tygstrup, 1961). In anuric patients the galactose elimination was not performed during peritoneal dialysis. For the statistical evaluation Fisher's exact test and the Mann-Whitney test were used.

\section{Results}

Twenty per cent of the patients survived $(95 \%$ confidence limits: $6 \cdot 8-40 \cdot 7 \%$ ).

There was no significant difference (Table 2) between those who survived and those who died as far as the following variables were concerned: sex, age, duration of disease before admission, duration of coma before or during admission, coma grade on admission, dominant frequency of the electroencephalogram, and liver dullness. No difference was found among surviving and non-surviving patients regarding treatment schedules, as outlined in Table 2. A low blood glucose level $(<2.0 \mathrm{mmol} / \mathrm{l})$ was recorded once in six of the patients who died. Persistent hypoglycaemia was not seen. In none of the survivors was hypoglycaemia recorded. In five of the patients who died cessation of cerebral blood flow was demonstrated. In none of these patients was hypoglycaemia recorded.

The results of the liver tests that were performed 
Table 2 Coma grade on admission, dominant frequency of EEG, liver size, different treatments, and possible concomitant causes of death

\begin{tabular}{|c|c|c|c|c|c|c|c|c|c|c|}
\hline \multirow{2}{*}{$\begin{array}{l}\text { Case } \\
\text { no. }\end{array}$} & \multirow{2}{*}{$\begin{array}{l}\text { Grade of } \\
\text { coma }(0-I V) \\
\text { on admission }\end{array}$} & \multirow{2}{*}{$\begin{array}{l}\text { First } E E G \\
\text { dominant frequency } \\
(\mathrm{Hz})\end{array}$} & \multirow[t]{2}{*}{ Liver dullness* } & \multicolumn{6}{|c|}{ Treatment } & \multirow{2}{*}{$\begin{array}{l}\text { Possible concomitant } \\
\text { cause of death }\end{array}$} \\
\hline & & & & $S$ & $P I$ & $E T$ & $P L P$ & $A V$ & $P D$ & \\
\hline 1 & III & NP & $\mathbf{D}$ & 0 & $\mathbf{0}$ & $x$ & 0 & 0 & 0 & - \\
\hline 2 & III & $2-3$ & $\mathbf{N}$ & 0 & 0 & $x$ & 0 & 0 & 0 & - \\
\hline 3 & III & $2-3$ & $\mathbf{N}$ & $x$ & 0 & 0 & 0 & 0 & 0 & - \\
\hline 4 & III & $1 \cdot 5-3$ & D & $x$ & 0 & $x$ & $x$ & $x$ & 0 & - \\
\hline 5 & IV & $1 \cdot 5-3$ & $\mathbf{D}$ & 0 & 0 & $x$ & 0 & $x$ & 0 & - \\
\hline 6 & I & $1 \cdot 5-3$ & $\mathbf{N}$ & $x$ & 0 & $x$ & 0 & 0 & 0 & Hypoglycaemia \\
\hline 7 & II & $3-4$ & D & 0 & $x$ & $x$ & $x$ & $x$ & $\mathbf{0}$ & Hyaline membranes in lungs \\
\hline 8 & II & 3 & $\mathbf{D}$ & 0 & 0 & $x$ & 0 & $x$ & 0 & Cardiac arrest \\
\hline 9 & III & $1-3$ & $\mathbf{N}$ & 0 & $x$ & $x$ & $\mathbf{0}$ & $\hat{x}$ & $\mathbf{0}$ & \\
\hline 10 & IV & $2-4$ & $\mathbf{N}$ & 0 & $\hat{0}$ & $\hat{0}$ & 0 & $\hat{x}$ & $\mathbf{0}$ & \\
\hline 11 & IV & $1 \cdot \overline{5}-3$ & D & $x$ & $x$ & $x$ & $\mathbf{0}$ & $x$ & 0 & $\begin{array}{l}\text { Hypoglycaemia, generalised } \\
\text { candidiasis infection }\end{array}$ \\
\hline 12 & IV & $1 \cdot 5-2$ & $\mathbf{D}$ & $x$ & $x$ & $x$ & $x$ & $x$ & $x$ & \\
\hline 13 & II & $2-3$ & $\mathbf{A}$ & 0 & 0 & 0 & 0 & $x$ & $x$ & Hypoglycaemia \\
\hline 14 & III & $2-4$ & D & 0 & $x$ & $x$ & $\mathbf{0}$ & $x$ & 0 & Hypoglycaemia \\
\hline 15 & III & $2-4$ & $\mathbf{N}$ & 0 & $x$ & $x$ & 0 & $\hat{0}$ & $x$ & \\
\hline 16 & III & $1 \cdot 5-3$ & D & 0 & $\hat{0}$ & $\hat{x}$ & 0 & $x$ & $\hat{0}$ & \\
\hline 17 & III & 0 & $\mathbf{A}$ & 0 & $\mathbf{0}$ & $x$ & 0 & $x$ & 0 & \\
\hline 18 & I & NP & $\mathbf{N}$ & $x$ & $x$ & $x$ & $x$ & $\hat{0}$ & 0 & Miliary tuberculosis \\
\hline 19 & III & $2-3$ & D & 0 & $x$ & 0 & 0 & $x$ & $\mathbf{0}$ & Cardiac arrest \\
\hline 20 & III & NP & $\mathbf{D}$ & 0 & $x$ & $x$ & $\mathbf{0}$ & $x$ & 0 & Hypoglycaemia \\
\hline 21 & 0 & 2 & $\mathbf{D}$ & 0 & 0 & $x$ & 0 & $x$ & $\mathbf{0}$ & \\
\hline 22 & 0 & NP & $\mathbf{N}$ & 0 & $x$ & $x$ & $\mathbf{0}$ & $\hat{0}$ & $x$ & Subphrenic absces \\
\hline 23 & 0 & 4-6 & $\mathbf{D}$ & $x$ & $x$ & $\hat{0}$ & 0 & 0 & $\hat{0}$ & \\
\hline 24 & III & $2-3$ & $\overline{\mathbf{D}}$ & 0 & $x$ & $x$ & 0 & $x$ & 0 & Subarachnoidal haemorrhage \\
\hline 25 & III & $2-4$ & $\mathbf{N}$ & 0 & 0 & 0 & $\mathbf{0}$ & $x$ & $\mathbf{0}$ & Hypoglycaemia \\
\hline
\end{tabular}

${ }^{*} \mathrm{~N}$ : normal. D: diminished. A: absent. NP: not performed. S: corticosteroids. PI: fresh frozen plasma. ET: exchange transfusion. PLP: pig liver perfusion. AV: assisted ventilation. PD: peritoneal dialysis.

GALACTOSE PROTHROMBIN BILIRUBIN TRANSAMINASES AMMONIA
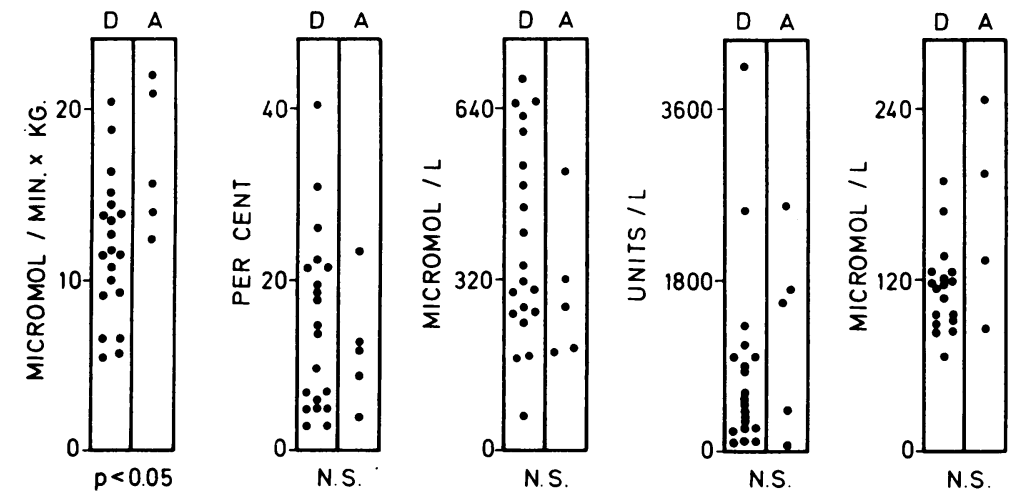

Fig. 1 Values of the galactose elimination capacity, prothrombin, bilirubin, transaminases, and ammonia in patients who died $(D)$, and those still alive $(A)$.

initially are shown in Fig. 1. The galactose elimination capacity was significantly lower $(P<0.05)$ in patients who died. The mean galactose elimination capacity was $17 \cdot 6 \pm 4.5$ (SD) and $12.2 \pm 4.3$ $\mu \mathrm{mol} \cdot \mathrm{min}^{-1} \cdot \mathrm{kg}^{-1}$, respectively. The results of repeated determination of the galactose elimination capacity are shown in Fig. 2. In patients who survived the galactose elimination capacity increased significantly. This was not the case in patients who died.

The other liver tests showed no significant difference between the two groups. 


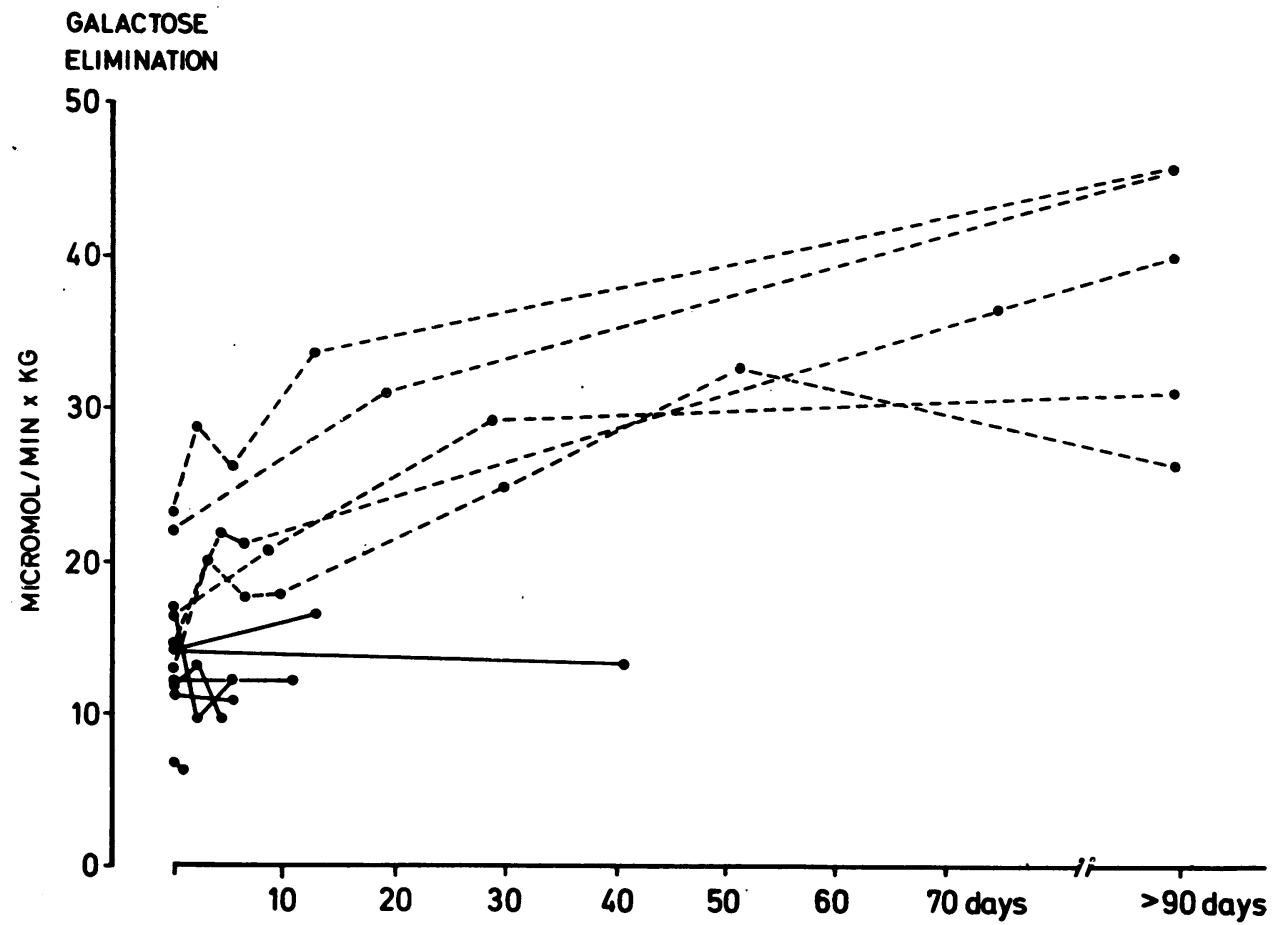

Fig. 2 Values of the galactose elimination capacity obtained at various intervals in the same patient. Broken lines: survivors; solid lines: fatal cases. The interval between the last galactose elimination capacity test performed and death varied from 0 to nine days.

In patients who survived the liver histology was normal three to 12 months after the coma episode. In the other patients liver histology at necropsy revealed subtotal or total liver cell necrosis.

\section{Discussion}

In our 25 patients with fulminant hepatic failure, none of the usual liver tests was of any value as prognostic markers. Neither the prothrombin value nor blood ammonia differed between those who survived and those who died. This is in accordance with works by Reynolds (1969), and by Saunders et al. (1972), but not with that of Demedts $e t$ al. (1974), who found blood ammonia to be significantly higher in nine patients who died, compared with five patients who survived. Furthermore, the initial prothrombin values were not significantly different but before a third exchange transfusion was performed the prothrombin value (percentage of normal) was significantly higher in the survivors.

Coagulation factor VIJ is probably a better prognostic marker than the prothrombin time, as shown by Dymock (1975). In 18 patients he found that all 10 patients with a factor VII concentration above
$9 \%$ survived, while eight patients with concentrations below $9 \%$ died.

Other proteins synthesised by the liver that are used as prognostic markers are $\alpha_{1}$ antitrypsin and $\alpha_{1}$ foetoprotein. Rueff et al. (1975) measured plasma concentrations of $\alpha_{1}$ antitrypsin in 24 patients with fulminant hepatitis and coma. In nine of 16 patients who died plasma concentrations were below 1.70 $\mathrm{mg} / \mathrm{ml}$, while only one of eight survivors had a concentration of $\alpha_{1}$ antitrypsin below that level $(\mathrm{P}<0.001)$.

Murray-Lyon et al. (1975) measured $\alpha_{1}$ foetoprotein in serum from 48 patients with fulminant hepatic failure. In seven of 17 survivors $\alpha_{1}$ foetoprotein was positive ( $>50 \mu \mathrm{g} / \mathrm{ml}$ ) compared with two of the $\mathbf{3 1}$ fatal cases. Although not all patients who recovered were foetoprotein positive the demonstration of this protein may indicate liver cell regeneration.

An evaluation of liver histology and prognosis has been performed in 38 patients by Opolon et al. (1975). Hepatocyte volume in liver biopsies from patients with fulminant hepatic failure was significantly smaller in patients who died, but approximately half of the cases had hepatocyte volumes 
corresponding with the survivors. The major drawback of the histological evaluation is, however, that most centres hesitate to perform liver biopsies in these patients because of the risk of bleeding, although this complication was not seen in Opolon's series.

Few quantitative liver function tests are available for the assessment of the liver function in fulminant hepatic failure. The conjugation of cholic acid was measured in 14 patients by Horak and Waldram (1975). The conjugation measured three hours after injection of labelled cholic acid was significantly $(\mathrm{P}<0.001)$ reduced in the six patients who died.

The metabolism of certain drugs may also be considered as a quantitative liver function test. In patients with paracetamol liver damage, the plasma half life of unchanged paracetamol was the most reliable early guide to prognosis (Prescott et al., 1971), but the material contained only one patient who developed hepatic coma. The clearance of phenazone was found to distinguish between patients with and without hepatic encephalopathy (Andreasen and Ranek, 1975), but its prognostic use in fulminant hepatic failure remains to be shown.

In the present material, no patient with fulminant hepatic failure having a galactose elimination capacity below $12.8 \mu \mathrm{mol} / \mathrm{min}$ and $\mathrm{kg}$ body weight survived. Analysis of the eight patients who died having a galactose elimination greater than 13 $\mu \mathrm{mol} / \mathrm{min}$ and $\mathrm{kg}$ body weight revealed that six (nos. 6,11, 12, 13, 15, and 23) ran a clinically subacute course, while the disease lasted longer than 30 days. One patient died from cardiac arrest (no. 19). The time interval from the beginning of the liver disease and the duration of coma before the patient enters the hospital varies considerably. In a patient who is admitted early in the course of the disease the liver function may further deteriorate after hospitalisation. Thus a relatively high galactose elimination capacity may be found on admission, although the patient subsequently dies from hepatic failure. This was seen in one patient (no. 21), who had a galactose elimination capacity of $16.9 \mu \mathrm{mol} /$ min and $\mathrm{kg}$ body weight on admission and $9.6 \mu \mathrm{mol}$ the following day. Repeated determinations of the galactose elimination capacity (Fig. 2) therefore make prognostication more reliable, which is, of course, also the case for most other tests.

The advantage of the galactose elimination capacity is that it is relatively simple to perform, especially if capillary blood is used instead of arterial blood, and it lasts only one hour, whereas most other metabolic investigations last several hours. It is not influenced by changes in hepatic blood flow or supportive treatments performed the same day, as, for example, exchange transfusion or infusion of fresh frozen plasma, which influence, for instance, prothrombin and bilirubin concentrations.

Although galactose elimination is not a vital function, it is probably a measure of the functioning liver cell mass (Tygstrup, 1966). A quantitative liver function test reflecting the metabolic capacity of the liver also contains prognostic information. If the metabolic capacity is low, it is reasonable to assume that the prognosis is bad.

It is of considerable practical value that quantitative liver function tests are further investigated and evaluated. They may make the evaluation of different treatments in acute liver failure more comparable by ensuring that patients with a similar degree of impaired liver function have been examined. The frequently optimistic preliminary reports on new treatments may be due to accidental selection of patients with a relatively good liver function. Another point of practical value is to determine whether a quantitative liver function test can define a critical level, indicating the minimum of liver function which permits the survival of the patient (a 'survival limit'). Similarly a 'regeneration limit' may exist, and from a possible difference between the 'survival limit' and the 'regeneration limit' it may be possible to estimate the amount of 'liver assist' that is needed. Finally, treatment of patients with liver function below the 'regeneration limit' can be omitted, unless a liver transplantation is performed.

In the present series a 'survival limit' corresponding to about $12 \mu \mathrm{mol}$ galactose metabolised/min and $\mathrm{kg}$ body weight is suggested, Whether this limit is influenced by the various types of supportive treatment given to some of the patients is unknown, but none of these treatments is of proven value. In patients with fulminant hepatic failure and a total duration of the disease less than five weeks this survival limit seems to be of prognostic significance. However, further investigation are needed. For instance the effect of age upon this 'survival limit' cannot be estimated in the present series.

\section{References}

Andreasen, P. B., and Ranek, L. (1975). Liver failure and drug metabolism. Scandinavian Journal of Gastroenterology, 10, 293-297.

Burnell, J. M., Runge, C., Saunders, F. C., Thomas, E. D., and Volwiler, W. (1973). Acute hepatic failure treated by cross circulation. Archives of Internal Medicine, 132, 493-498.

Demedts, M., De Groote, J., Vandamme, B., and Desmet, V. J. (1974). Discriminative and prognostic signs in acute hepatic coma, treated by exchange transfusions. Digestion, 11, $105-114$.

Dymock, I. W. (1975). Assessment of survival prospects in acute hepatic failure-The value of a coagulation screen. In Artificial Liver Support, pp. 290-297. Edited by R. 
Williams and I. M. Murray-Lyon. Pitman: Tunbridge Wells.

Eiseman, B., Liem, D. S., and Raffucci, F. (1965). Heterologous liver perfusion in treatment of hepatic failure. Annals of Surgery, 162, 329-345.

Gazzard, B. G., Weston, M. J., Murray-Lyon, I. M., Flax, H., Record, C. O., Portmann, B., Langley, P. G., Dunlop, E. H., Mellon, P. J., Ward, M. B., and Williams, R. (1974). Charcoal haemoperfusion in the treatment of fulminant hepatic failure. Lancet, 1, 1301-1306.

Horak, W., and Waldram, R. (1975). Bile acid conjugation in fulminant hepatic failure. In Artificial Liver Support, pp. 283-285. Edited by R. Williams and I. M. MurrayLyon. Pitman: Tunbridge Wells.

Karvountzis, G. G., Redeker, A. G., and Peters, R. L. (1974). Long term follow-up studies of patients surviving fulminant viral hepatitis. Gastroenterology, 67, 870-877.

Kurz, G., and Wallanfalz, K. (1970). D-galactose, UV-test und Galactose-Dehydrogenase. In Methoden der enzymatischen Analyse, 2nd edn, pp. 1241-1249. Edited by H. U. Bergmeyer. Verlag Chemie: Weinheim.

Murray-Lyon, I. M., Orr, H., Kohn, J., and Williams, R. (1975). Serum alpha-fetoprotein in fulminant hepatic failure. In Artificial Liver Support, pp. 278-282. Edited by R. Williams and I. M. Murray-Lyon. Pitman: Tunbridge Wells.

Opolon, P., Scotto, J., Eteve, J., Vergoz, D., Thomas, M., and Caroli, J. (1975). Liver biopsy and prognosis in acute liver failure. In Artificial Liver Support, pp. 271-277. Edited by R. Williams and I. M. Murray-Lyon. Pitman: Tunbridge Wells.

Prescott, L. F., Roscoe, P., Wright, N., and Brown, S. S. (1971). Plasma-paracetamol half-life and hepatic necrosis in patients with paracetamol overdosage. Lancet, 1, 519-522.

Ranek, L., Iversen Hansen, R., Hilden, M., Ramsøe, K., Schmidt, A., Winkler, K., and Tygstrup, N. (1971). Pig liver perfusion in the treatment of acute hepatic failure. Scandinavian Journal of Gastroenterology, suppl. 9, 161-169.

Reynolds, T. B. (1969). Exchange transfusion in fulminant hepatic failure. Gastroenterology, 56, 170-171.

Rueff, B., Morin, T., Martin, J.-P., Feldmann, G., Ropartz, C., and Benhamou, J. P. (1975). Alpha ${ }_{1}$ antitrypsin and fulminant hepatitis (Abstract). Gastroenterology, 68, 1084.

Saunders, S. J., Hickman, R., MacDonald, R., and Terblanche, J. (1972). The treatment of acute liver failure. In Progress in Liver Disease, vol. 4, pp. 333-344. Edited by $H$. Popper and F. Schaffner. Grune and Stratton: New York.

Saunders, S. J., and Terblanche, J. (1975). Prognosis in acute hepatic failure. In Artificial Liver Support, pp. 217-222. Edited by R. Williams and I. M. Murray-Lyon. Pitman: Tunbridge Wells.

Trey, C., Burns, D. G., and Saunders, S. J. (1966). Treatment of hepatic coma by exchange blood transfusion. New England Journal of Medicine, 274, 473-481.

Tygstrup, N. (1961). The urinary excretion of galactose and its significance in clinical intravenous galactose tolerance tests. Acta Physiologica Scandinavica, 51, 263-274.

Tygstrup, N. (1966). Determination of the hepatic elimination capacity $(\mathrm{Lm})$ of galactose by single injection. Scandinavian Journal of Clinical and Laboratory Investigation, 18, 118-125. 